\title{
Grateful Experience and Upstream Reciprocity Behavior
}

\author{
Shueh-Chin Ting ${ }^{1, *}$ \\ ${ }^{1}$ Department of Education, National University of Tainan, Taiwan \\ *Corresponding author: Department of Education, National University of Tainan, Taiwan. \\ E-mail: tingsc@ms49.hinet.net
}

Received: September 6, 2018 Accepted: December 21, 2018 Published: December 25, 2018

doi:10.5296/ije.v10i4.14010 URL: https://doi.org/10.5296/ije.v10i4.14010

\begin{abstract}
In a utilitarian society, advocating gratitude is very important. Gratitude can improve social harmony. Enhancing gratitude should start from education. However, in academic research, some gaps in gratitude have yet to be clarified. The focus of the present study is the relationship between grateful experiences and upstream reciprocity behavior. Past research has shown that gratitude promotes reciprocity but mainly emphasizes mutual help between benefactors and beneficiaries. The present study expands on the concept of upstream reciprocity, which is reciprocating help to a third party instead of returning it to one's benefactors, to explore whether university students rich in grateful experiences are more likely to display upstream reciprocity behaviors. Using questionnaires, the present study collected a total of 681 valid questionnaires to conduct an empirical study. The present study found grateful experiences of university students enhance their upstream reciprocity behaviors.
\end{abstract}

Keywords: Benefactor, Beneficiary, Gratitude, Upstream reciprocity 


\section{Introduction}

Previous studies have shown that the concept of reciprocity is the display of altruistic behavior by grateful people when they receive help from others, even if it is time- or cost-consuming (Bartlett, Condon, Cruz, Baumann, \& Desteno, 2012). Although past studies have shown that gratitude produces reciprocity (Dewani, Sinha, \& Mathur, 2016), the question of to whom has yet to be answered completely. It is clear that the beneficiary reciprocates to the benefactor, but to date, it is still unclear whether behaviors that help unrelated third parties are derived. However, Nowak and Roch (2007) have indicated that gratitude may evolve into upstream reciprocity - that is, the beneficiary may pass on the benefits to someone other than the benefactor as a result of being grateful — which has yet to be sufficiently supported. The present study does not deny that the beneficiary reciprocates to the benefactor as a result of being grateful. However, with the accumulation of grateful experiences, the beneficiary may do unto the others what others have done to them, producing motives and behaviors to help the others, which is the motive of the present study.

Based on the aforementioned research motive, the question awaiting to be answered in the present study is whether the reciprocity behavior directed at unrelated third parties (upstream reciprocity) can be derived from the beneficiary's grateful experience.

\section{Gratitude}

McCullough, Kilpatrick, Emmons, and Larson (2001) believed that gratitude is an emotional response to valuable help that is provided by others intentionally and non-obligatorily and at a cost. McCullough, Kimeldorf, and Cohen (2008) defined gratitude as the positive emotion produced when individuals benefit from the costly, intentional, and voluntary behavior of others.

In terms of factors influencing gratitude, Tsang (2006b) found that gratitude is related to the motives of the benefactor providing help. The study participants felt more gratitude if the benefactor's motives were benevolent than if the motives were self-serving. Pelser, de Ruyter, Wetzels, Grewal, Cox, and van Beuningen (2015) indicated that benevolent motives produce gratitude, and if one's benefits come from other's efforts, one will be grateful. Tsang (2006a) found that the party on the receiving end of the benefits is more grateful and has more positive emotions when the benefactor makes conscious efforts to benefit the other party than when the benefactor makes unconscious efforts. Expensive favors have more ability to evoke gratitude than inexpensive favors (Pelser, de Ruyter, Wetzels, Grewal, Cox, \& van Beuningen, 2015). In terms of the type of favors, Dewani, Sinha, and Mathur (2016) found that social and structural relationship investments create gratitude in customers, which in turn increases customer loyalty. However, financial relationship investments produce a sense of obligation in customers, decreasing customer loyalty.

Regarding the results of gratitude's influence, Lin (2015) found that gratitude alleviates depression through the mediation of self-esteem and psychological well-being. Lin (2016) found that social support and problem coping have a partial mediating effect on gratitude and 
well-being. In terms of research related to reciprocity, Bartlett and DeSteno (2006) discovered that those who are grateful make more efforts to help the benefactor than those who are not. In addition, the beneficiary's expression of gratitude fortifies the benefactor's helpful actions. For example, McCullough, Kimeldorf, and Cohen (2008) found that the beneficiary's expression of gratitude to the benefactor fortifies the benefactor's generous behavior. McCullough, Kilpatrick, Emmons, and Larson (2001) proposed that the beneficiary's expression of gratitude reinforces the benefactor to display prosocial behavior in the future.

\section{Upstream Reciprocity}

The general view of past studies is that the grateful beneficiary finds opportunities to help the benefactor based on reciprocity, triggering a direct reciprocal behavior, but gratitude may also evolve into what Nowak and Roch (2007) call upstream reciprocity - that is, the beneficiary directs the benefits to a third party and not to the benefactor, especially at a time the benefactor does not need help. Through computer simulations, Nowak and Roch concluded that if people's direct reciprocity has started to evolve, gratitude will stimulate people to help third parties at no cost, which is conducive to improving society. We believe that evolution in this regard can be achieved through relying on the accumulation of grateful experiences.

Bartlett and DeSteno (2006) found that research participants who are grateful are more likely to help strangers than research participants who are not grateful, a finding that breaks away from the concept of reciprocity. Gratitude may promote prosocial behavior through its effects on mental state. Dunn and Schweitzer (2005) found that participants who recalled being grateful to someone are more trusting of a third party than those who recalled feeling angry, guilty, and proud towards someone, though this only holds true when they are very unfamiliar with the third party. Jackson, Lewandowski, Fleury, and Chin (2001) showed that research participants who recalled grateful experiences in their personal lives attribute other people's good fortune to real reasons that are under their control, so grateful people are more likely to compliment other people's accomplishments. Trust and readiness to compliment other's accomplishments are important lubricants for positive social interactions. These psychological effects may explain why gratitude promotes prosocial behavior (McCullough, Kimeldorf, \& Cohen, 2008). Based on the description above, the richer in experiences in gratitude a university student is, the healthier the mental state, the more likely to treat those in their surrounding with tolerance and optimism, and the more likely to possess the mindset and passion of helping others. Therefore, we infer Hypothesis 1.

H1: University students rich in grateful experiences are more likely to display upstream reciprocity. 


\section{Research Methods and Study Results}

The operational definition of gratitude in the present study is the number or frequency of positive mental state and emotions felt by university students when they receive help from others.

Regarding the measurement tools for grateful experiences in the present study, we referenced the scale developed by Ting (2015) to assess white-collar workers' gratitude. The scale showed that the reliability for each item on gratitude was between 0.58 and 0.78 , and the composite reliability of gratitude was 0.85 , indicating that the gratitude scale had excellent internal consistency. The ratio of chi-square to degree of freedom $(x 2 / \mathrm{df})$ for the gratitude model was less than 3 at 2.21, standardized root mean square residual (SRMR) was less than 0.05 at 0.03 , goodness of fit index (GFI) was larger than 0.9 at 0.95 , adjusted goodness of fit index (AGFI) was greater than 0.9 at 0.92 , confirmatory fit index (CFI) was greater than 0.95 at 0.99 , and root mean square error of approximation (RMSEA) was less than 0.08 at 0.05 , indicating that the gratitude scale has excellent fit. In addition, the factor loadings for each item in the gratitude scale were between 0.76 and 0.88 , greater than 0.5 . The average variance extracted (AVE) measured of gratitude was 0.76 , which is greater than 0.5 , indicating that the gratitude scale has excellent convergent validity.

While the scale was designed to measure the subjects' level of gratitude to a single event, the present study examined grateful experiences, which is accumulated over time and different from that of Ting (2017). Therefore, we selected five items from the twelve items assessing the level of gratitude by Ting (2017) and slightly modified the text to be suitable as a measuring tool for grateful experiences in the present study. The items are as displayed in Table 1.

Table 1. Items Assessing Grateful Experiences

\begin{tabular}{l}
\hline Item \\
\hline I often have people helping me by my side. \\
Those who help me often do it sincerely. \\
The help given to me by others is often non-obligatory. \\
Many of my friends are people who have helped me in the past. \\
My friends often make me feel warm inside.
\end{tabular}

The operational definition of upstream reciprocity in the present study is the behavior of a university student to help a third party (a person who has not helped the student in the past).

Past studies lacked tools that directly measured upstream reciprocity behavior. Based on the definition of upstream reciprocity behavior, we referenced the prosocial behavior scale of Carlo and Randall (2002) and selected five items to assess upstream reciprocity behavior, which are as displayed in Table 2. The prosocial behavior scale of Carlo and Randall (2002) 
was established using university students as the subjects in the undergraduate department, similar to that of the present study. With a total of 23 items and 6 subscales and reliability between 0.63 and 0.85 , the study indicated that the scale has excellent internal consistency, temporal stability, construct validity, discriminant validity, convergent validity, and predictive validity.

Table 2. Items Assessing Upstream Reciprocity

Item
I find that when someone is in a bad mood, I will take the initiative to comfort him/her.
When someone needs help, I will take the initiative to help him/her.
I do not hesitate to help when someone asks me to.
When I see that someone is injured, I will take the initiative to help him/her.
I do not intentionally make it known to others that I have helped someone.

The present study collected data through the questionnaire survey method and distributed questionnaires in a random manner to university students in three cities: Tainan, Kaohsiung and Pingtung. A total of 800 questionnaires were distributed, and 720 were collected. After excluding incomplete questionnaires and questionnaires that were answered in a pattern, a total of 681 valid questionnaires were received. Analysis of the study sample is as follows.

The present study had five items on grateful experiences and five items on upstream reciprocity behavior for a total of ten items, all of which underwent exploratory factor analysis (EFA). Principal component analysis (PCA) was used to extract factors, of which two factors with an eigenvalue greater than 1 were extracted, and using Kaiser normalization with varimax method, orthogonal rotation was performed. Results are shown in Table 4. The five items on grateful experiences clustered at Factor 2 with the smallest factor loading at 0.726, while upstream reciprocity behavior items clustered at Factor 1 with the smallest factor loading at 0.680 . All factor loadings were greater than 0.5 . Items for measuring grateful experiences and upstream reciprocity are completely separated, so the results extracted are completely consistent with theory, and the cumulative explained variation was $68.927 \%$, indicating that the assessment of grateful experiences and upstream reciprocity behavior have excellent validity. In addition, Cronbach's $\alpha$ of the five items for grateful experiences was 0.869 while Cronbach's $\alpha$ for upstream reciprocity behavior was 0.896 , indicating that the assessment of grateful experiences and upstream reciprocity behavior have excellent reliability. 
Table 3. Study Sample (N=681)

\begin{tabular}{|c|c|c|c|}
\hline & Category & $\mathrm{N}$ & Percentage \\
\hline \multirow[t]{6}{*}{ Grade } & Freshmen & 142 & 20.9 \\
\hline & Sophomore & 138 & 20.3 \\
\hline & Junior & 150 & 22.0 \\
\hline & Senior & 99 & 14.5 \\
\hline & Master's program & 126 & 18.5 \\
\hline & $\mathrm{PhD}$ program & 26 & 3.8 \\
\hline \multirow[t]{2}{*}{ Gender } & Male & 233 & 34.2 \\
\hline & Female & 448 & 65.8 \\
\hline \multirow[t]{5}{*}{ Age } & Under 20 & 169 & 24.8 \\
\hline & 20 to under 25 & 359 & 52.7 \\
\hline & 25 to under 30 & 22 & 3.2 \\
\hline & 30 to under 40 & 43 & 6.3 \\
\hline & Over 40 & 88 & 12.9 \\
\hline \multirow{4}{*}{$\begin{array}{l}\text { Number of siblings } \\
\text { (including myself) }\end{array}$} & 1 person & 107 & 15.7 \\
\hline & 2 people & 265 & 38.9 \\
\hline & 3 people & 208 & 30.5 \\
\hline & Over 4 people & 101 & 14.8 \\
\hline \multirow[t]{9}{*}{ Institution attending } & Literature & 111 & 16.3 \\
\hline & Law & 1 & 0.1 \\
\hline & Business & 241 & 35.4 \\
\hline & Medicine & 50 & 7.3 \\
\hline & Agriculture & 1 & 0.1 \\
\hline & Engineering & 8 & 1.2 \\
\hline & Science & 28 & 4.1 \\
\hline & Education & 84 & 12.3 \\
\hline & Others & 157 & 23.1 \\
\hline \multirow[t]{6}{*}{ Economic resources } & Completely from family & 181 & 26.6 \\
\hline & Mostly from family & 167 & 24.5 \\
\hline & $\begin{array}{l}\text { Split evenly between family and } \\
\text { myself }\end{array}$ & 105 & 15.4 \\
\hline & Mostly from myself & 84 & 12.3 \\
\hline & Completely from myself & 139 & 20.4 \\
\hline & Others & 5 & 0.7 \\
\hline
\end{tabular}




\section{1) Macrothink}

International Journal of Education

ISSN 1948-5476

2018, Vol. 10, No. 4

Table 4. Factor Loadings and Explained Variation of EFA after Rotation

\begin{tabular}{lrr}
\hline & Factor 1 & Factor 2 \\
\hline G1 & .294 & .766 \\
G2 & .365 & .743 \\
G3 & .113 & .785 \\
G4 & .253 & .780 \\
G5 & .388 & .726 \\
U1 & .789 & .316 \\
U2 & .866 & .274 \\
U3 & .787 & .286 \\
U4 & .860 & .221 \\
U5 & .680 & .236 \\
Eigenvalue & 5.582 & 1.311 \\
Explained variation\% & 55.820 & 13.107 \\
Cumulative explained variation\% & 55.820 & 68.927 \\
\hline
\end{tabular}

Note: $\mathrm{G}$ indicates grateful experience while $\mathrm{U}$ indicates upstream reciprocity behavior

After validity and reliability analysis, the present study averaged the scores of the five items for grateful experiences to represent the score of grateful experiences and averaged the five items of upstream reciprocity behavior to represent the score of upstream reciprocity behavior. Regression analysis was performed to illustrate the relationship between grateful experiences and upstream reciprocity behavior. The direction of the regression coefficient and significance were used to determine whether $\mathrm{H} 1$ is established, and $\mathrm{R}^{2}$ was used to determine the explanatory power of grateful experiences on upstream reciprocity behavior. Adjusted $\mathrm{R}^{2}$ was .386 , indicating that grateful experiences can account for $38.6 \%$ of the variation in upstream reciprocity behavior. Other data are shown in Table 5 and Table 6. Table 5 displays the analysis of variance (ANOVA) for the regression model, of which the $\mathrm{F}$ value for the overall model was 429.192, reaching a significant level of $\mathrm{p}<0.001$. Table 6 provides the results of the coefficient verification for the regression model. The standardized coefficient of grateful experiences was .622 , and the $t$ value determined by coefficient verification was 20.717, reaching a significant level of $p<0.001$. Therefore, the present study gives Hypothesis 1 , which posits that university students rich in grateful experiences are more likely to display upstream reciprocity, empirical support. 
Table 5. ANOVA of the Regression Model

\begin{tabular}{lrrrrr}
\hline & & $\begin{array}{r}\text { Degree of } \\
\text { freedom }\end{array}$ & $\begin{array}{c}\text { Mean } \\
\text { square }\end{array}$ & \multicolumn{1}{c}{ F } & Significance \\
\hline Regression & 254.317 & 1 & 254.317 & 429.192 & .000 \\
Residual & 402.339 & 679 & .593 & & \\
Total & 656.656 & 680 & & & \\
\hline
\end{tabular}

Table 6. Coefficient Verification of the Regression Model

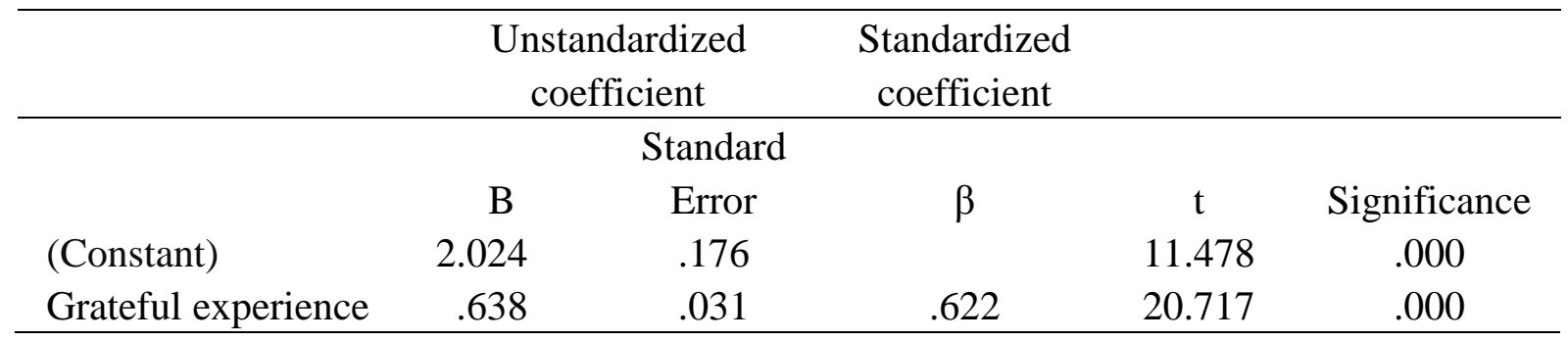

\section{Conclusion and Suggestions}

Gratitude can be an important personality trait, and it can also be an important positive emotion. Whether from the perspective of enhancing personality traits or cultivating positive emotions, gratitude is a topic worthy of attention. The present study expands from past research on gratitude to upstream reciprocity behavior. By collecting data through questionnaires and verifying the hypothesis through regression analysis, the present study found that university students rich in grateful experiences are more likely to display upstream reciprocity behavior. Upstream reciprocity behavior is a relatively new concept; past research only indicated that gratitude leads to returns to the benefactor, which is the so-called direct reciprocity. However, reciprocation to a third party has not been clarified, which is a kind of indirect reciprocity. Indirect reciprocity has been conceptually explained in past studies and includes upstream reciprocity and downstream reciprocity. Upstream reciprocity refers to the beneficiary helping a third party after receiving help from the benefactor, while downstream reciprocity refers to the benefactor receiving help from a third party after helping the beneficiary, but both lack empirical research. Based on empirical research on university students, the present study found that university students rich in grateful experiences are more likely to display upstream reciprocity behavior. Therefore, the present study provides evidence for the relationship between gratitude and upstream reciprocity, breaking through the previous notion that gratitude leads to returns. One important contribution of the present study is that the object of gratitude's reciprocation is not limited to the benefactor and can be returned to a third party.

As for practical advice, the present study found that university students rich in grateful experiences are more likely to display upstream reciprocity behavior. Based on this, promoting university students to help others should start with how to make university 


\section{Macrothink}

students feel grateful. In addition, to increase grateful experiences, it is necessary to trigger gratitude from different aspects to accumulate grateful experiences quickly. After such efforts, the realm of doing unto others what others have done to oneself will be reached, as upstream reciprocity is the manifestation of that.

Width

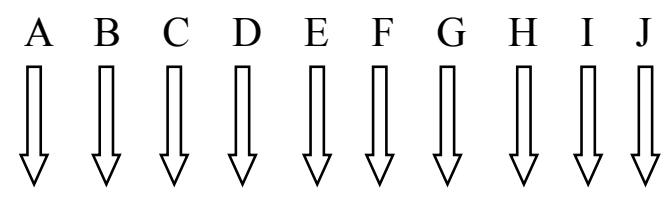

Depth

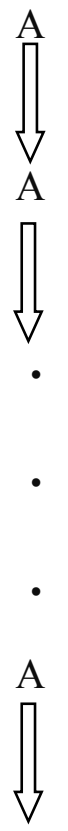

Figure 1. Grateful Experiences from the Width or the Depth

In terms of suggestions for future studies, we recommend exploring the width and depth of grateful experiences. The grateful experiences in the present study refer to experiences accumulated over time, but the items have a predilection to measure the frequency of grateful experiences - for example, "I often have people helping me by my side", "Those who help me often do it sincerely", and "My friends often make me feel warm inside". If grateful experiences are studied from the width or depth of the experience the beneficiary comes in contact with, will the results be more refined? For example, is the upstream reciprocity behavior the same if the beneficiary comes in contact with ten types of gratitude event once (width) or if the beneficiary comes in contact with a single type of gratitude event for ten times (depth)? 


\section{Acknowledgements}

The author is grateful to Ministry of Science and Technology in Taiwan for the financial support (MOST 106-2410-H-024-012-SSS).

\section{References}

Bartlett, M. Y., \& DeSteno, D. (2006). Gratitude and prosocial behavior: Helping when it $\begin{array}{llll}\text { costs you. Psychological } & \text { Science, } & \text { 319-325. }\end{array}$ https://doi.org/10.1111/j.1467-9280.2006.01705.x

Bartlett, M. Y., Condon, P., Cruz, J., Baumann, J., \& Desteno, D. (2012). Gratitude: Prompting behaviours that build relationships. Cognition and Emotion, 26(1), 2-13. https://doi.org/10.1080/02699931.2011.561297

Carlo, G., \& Randall, B. A. (2002).The development of a measure of prosocial behaviors for late adolescents. Journal of Youth and Adolescence, 31(1), 31-44. https://doi.org/10.1023/A:1014033032440

Dewani, P. P., \& Sinha, P. K. (2012). Gratitude: An emotional approach in business relationship. Research Journal of Business Management, 6(1), 1-11. https://doi.org/10.3923/rjbm.2012.1.11

Dewani, P. P., Sinha, P. K., \& Mathur, S. (2016). Role of gratitude and obligation in long term customer relationships. Journal of Retailing and Consumer Services, 31, 143-156. https://doi.org/10.1016/j.jretconser.2016.01.005

Dunn, J. R., \& Schweitzer, M. E. (2005). Feeling and believing: The influence of emotion on trust. Journal of Personality and Social Psychology, 88(5), 736-748. https://doi.org/10.1037/0022-3514.88.5.736

Jackson, L. A., Lewandowski, D. A., Fleury, R. E., \& Chin, P. P. (2001). Effects of affect, stereotype consistency, and valence of behavior on causal attributions. Journal of Social Psychology, 141(1), 31-48. https://doi.org/10.1080/00224540109600521

Lin, C. C. (2015). Gratitude and depression in young adults: The mediating role of self-esteem and well-being. Personality and Individual Differences, 87, 30-34. https://doi.org/10.1016/j.paid.2015.07.017

Lin, C. C. (2016). The roles of social support and coping style in the relationship between gratitude and well-being. Personality and Individual Differences, 89, 13-18. https://doi.org/10.1016/j.paid.2015.09.032

McCullough, M. E., Kilpatrick, S. D., Emmons, R. A., \& Larson, D. B. (2001). Is gratitude a moral affect? Psychological Bulletin, 127(2), 249-266. https://doi.org/10.1037/0033-2909.127.2.249

McCullough, M. E., Kimeldorf, M. B., \& Cohen, A. D. (2008). An adaptation for altruism? 
The social causes, social effects, and social evolution of gratitude. Current Directions in Psychological Science, 17(4),

281-285. https://doi.org/10.1111/j.1467-8721.2008.00590.x

Nowak, M., \& Roch, S. (2007). Upstream reciprocity and the evolution of gratitude. Proceedings of the Royal Society of London, Series B: Biological Sciences, 274, 605-609. https://doi.org/10.1098/rspb.2006.0125

Pelser, J., de Ruyter, K., Wetzels, M., Grewal, D., Cox, D., \& Beuningen, J. (2015). B2B channel partner programs: Disentangling indebtedness from gratitude. Journal of Retailing, 91(4), 660-678. https://doi.org/10.1016/j.jretai.2015.05.006

Ting, S. C. (2017). The development of measurement tools of gratitude and external indebtedness. The Journal of Global Business Management, 13(2), 27-36.

Tsang, J. A. (2006a). Gratitude and prosocial behavior: An experimental test of gratitude. Cognition and Emotion, 20(1), 138-148. https://doi.org/10.1080/02699930500172341

Tsang, J. A. (2006b). The effects of helper intention on gratitude and indebtedness. Motivation and Emotion, 30(3), 198-204. https://doi.org/10.1007/s11031-006-9031-z

\section{Copyright Disclaimer}

Copyright for this article is retained by the author(s), with first publication rights granted to the journal.

This is an open-access article distributed under the terms and conditions of the Creative Commons Attribution license (http://creativecommons.org/licenses/by/3.0/). 